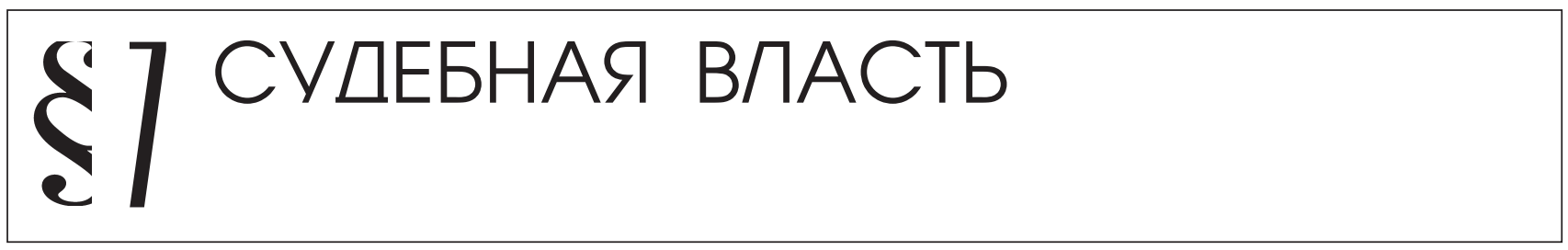

Герасимова A.E.

\title{
ИСТОРИЯ И СОВРЕМЕННОСТЬ ПРИНЦИПА РАВНОЙ ПРАВОВОЙ ЗАЩИТЫ В США (НА ПРИМЕРЕ ПРЕОДОЛЕНИЯ РАСОВОЙ ДИСКРИМИНАЦИИ)
}

\begin{abstract}
Аннотация: В рамках настоящей статьи автором рассматриваются вопросы, связанные с историей становления принципа равной правовой защиты закона («еqual protection of law») на протяжении периода с принятия XIV поправки к Конституции США до настоящего времени. Через призму прецедентного права проанализированы такие явления, как дискриминачия и позитивная дискриминация, политика «позитивных мер» Правительства США, механизмы проверки наличия или отсутствия в том или ином акте органов государственной власти признаков дискриминачии. В рамках исследования автором используется сравнительно-правовой и исторический методы исследования, особое внимание уделено анализу первичных источников - прецедентов Верховного суда США. Автором делаются выводы о наличии двух этапов дискриминаиии афроамериканского населения: прямой дискриминации и позитивной дискриминачии. В качестве механизма предотвращения дискриминации автором рассматривается метод "строгой проверки", выработанный в прецедентах Верховного суда США. Данный механизм, полагаем, может быть использован и для предотвращения дискриминации в иных социальных областях, в связи с чем, его применение могло бы обогатить и отечественную правовую науку и практику применения.
\end{abstract}

Ключевые слова: Равная защита закона, дискриминачия, позитивная дискриминация, Верховный суд США, Четырнадиатая поправка, США, Конституция США, Главенствующий государственный интерес, Пятая поправка, Строгая проверка.

Abstract: This article examines the issues associated with the history of emergence of the principle of equal protection of the laws throughout the period since the introduction of the 14th amendment to the U.S. Constitution until present time. Through the prism of legal precedent, the author analyzes such phenomena as discrimination and positive discrimination, the "positive measures" policy of the US government, and mechanisms of verification of presence or absence of signs of discrimination within any given act of the branches of government. The author makes a conclusion on the existence of two types of discrimination of African-American population: direct discrimination and positive discrimination. As a mechanism for deterring discrimination, the author examines the method of "strict scrutiny" formed by the legal precedent of the Supreme Court of the United States. This mechanism could be used to prevent discrimination in other social areas, thus its application could also enrich the Russian legal science and practice.

Keywords: U.S. Constitution, USA, 14th Amendment, Supreme court of the United States, positive discrimination, discrimination, equal protection, public interest, 5th Amendment, Strict scrutiny.

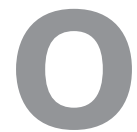

дной из традиционных гарантий, закрепленных конституциями большинства демократических государств, является гарантия равной правовой защиты.

Данное положение, по своей сути, направлено на защиту лица от различного рода дискриминаций, то есть ущемления в правах той или иной группы лиц в зависимости, в частности, от пола, расы, национальности, религии и т.п.
В рамках настоящей статьи нами будет рассмотрен вопрос о правовых механизмах преодолении расовой дискриминации на примере становления прав афроамериканского населения в США.

Исторически проблема расовой дискриминации в США была обусловлена существованием крупных плантаций в южных штатах, для возделывания которых «южанами» использовался труд «чернокожих» рабов, завозившихся из Африки. 
Первым шагом в правовом разрешении данного вопроса стало принятие в 1865 году XIV поправки к Конституции США, согласно которой ни один штат не может отказать какому-либо лицу в пределах своей юрисдикции в равной защите законов.

Вместе с тем, на практике данная норма не сразу нашла поддержку со стороны судов, которые длительное время ссылались на надуманные теории, отказываясь применять XIV поправку согласно ее «духу» и заложенной в нее демократической идее равенства.

В рамках дела Strander v. West Virginia (1880) Верховный суд США сформировал подход, согласно которому равная правовая защита не подразумевает принятия равных законов для «белого» и «черного» населения.

Еще одной печально известной доктриной, искажающей смысл XIV поправки, является доктрина «раздельных, но равных возможностей». Примечательным здесь является дело Plessy v. Ferguson (1896), в рамках которого Верховный суд США признал конституционным закон штата, предписывавший раздельный проезд «белых» и «черных» граждан в поездах.

Также широкое распространение получил подход, согласно которому суды буквально «прочитывали» требования XIV поправки и отмечали, что поскольку в ней речь идет только о штатах, то дискриминация со стороны частных лиц никак не затрагивается клаузой о равной правовой защите. Данный подход именуется в научной литературе «доктриной государственных действий ${ }^{[1]} \mathrm{B}$ частности, она была применена в деле Burton v. Wilmington Parking Authority (1961), где Верховный суд признал неконституционным «Закон о гражданских правах» 1875 года.

Соответственно, на первом этапе идея равенства устоялась на законодательном уровне, но не получила поддержки в судебной практике, в связи с чем, осталась декларативной, не действующей.

Новой вехой в применении XIV поправки к Конституции США стало решение по делу Brawn v. Board of Education (1954), в рамках которого Верховный суд США признал учреждение раздельных школ для «белого» и «черного» населения расовой дискриминацией, противоречащей Конституции США. Вопреки предшествующей негативной практике в данном деле XIV поправка была применена по существу.

Руководствуясь прецедентом по делу Brawn v. Board of Education, Верховный суд США в последующие годы распространил идею о неконституционности дискриминации афроамериканского населения в самые разные области социальных отношений: были устранены сегрегационные барьеры на транспорте и в местах, открытых для публики: парках, плавательных бассейнах, ресторанах, закусочных и т.д.; судом были отменены законы штатов, запрещавшие межрасовые браки и предусматривающие уголовные наказания за межрасовые внебрачные связи и т.д. ${ }^{[2]}$

Вместе с тем, параллельно с указанным процессом распространение начало получать обратное явление-позитивная дискриминация, которая выражается в предоставлении определенных привилегий тем слоям населения, которые в течение длительного периода времени находились в наиболее ущемленном положении. Правительство начало вводить целый ряд программ «позитивных мер» (affirmative action), направленных на предоставление преимуществ при приеме на работу, зачислении в школы, университеты афроамериканскому населению.

Соответственно, на втором этапе можно заметить обратный дисбаланс прав «белого» и «черного» населения, обусловленный чрезмерным желанием государства исправить историческую несправедливость.

Одним из первых дел, в рамках которого была предпринята попытка разрешить данную проблему, стало Regents of the University of California v. Bakke (1978), где Верховный суд США отменил квоты для национальных меньшинств при поступлении в университеты. Такие квоты позволяли, в частности, афроамериканцам получать значительные привилегии по сравнению с «белым» населением при поступлении в университеты, даже при наличии меньшего объема навыков и знаний.

Вместе с тем, следует отметить, что отменяя политику квот, Верховный суд США также указал, что учет расы человека при предоставлении привилегий возможен в целях компенсации результатов долгой социальной дискриминации, и такое предоставление привилегий не нарушает конституционных положений о равной защите со стороны закона (доктрина «коррелирующей дискриминации»).

В связи с двоякостью позиции Суда встает вопрос, где же все-таки находится грань между дискриминацией по признаку расы, позитивной дискриминацией и равенством.

Для решения указанного вопроса Верховным судом США выработана, так называемая, доктрина «строгой проверки» (strict scrutiny), которая заключается в следующем.

Для того чтобы акт, устанавливающий различия между несколькими группами лиц, был признан конституционным необходимо доказать следующие обстоятельства:

(1) установление классификации (различий в правовом положений) было обусловлено наличием главенствующего государственного интереса и направлено исключительно и непосредственно на достижение данного интереса; 
DOI: $10.7256 / 1811-9018.2015 .6 .14933$

При цитировании этой статьи сноска на dоі обязательна

\section{Право и политика 6 (186) 2015}

(2) отсутствуют альтернативные средства реализации такого главенствующего государственного интереса. В качестве главенствующего государственного интереса могут выступать, в частности, национальная безопасность, охрана жизни большого количества людей и т.д.

Важной гарантией здесь является введение презумпции «незаконности» классификации лиц в зависимости от расы и перекладывание бремени доказывания на государство.

Таким образом, как отмечается в литературе, одновременно достигается две цели: выявление незаконных мотивов правительства при принятии тех или иных актов и соотношение преимуществ - затрат от действий государства по установлению классификации в сравнении с ограничением конституционных прав и свобод, которые традиционно имеют высшую ценность ${ }^{[3]}$.

Полагаем, что на данном этапе уже сформировано определенное количество, в той или иной мере, действующих механизмов преодоления расовой дискриминации, тем не менее, указанный путь еще не завершен в связи с отсутствием четких рамок понимания главенствующего государственного интереса, что, возможно, и станет новым этапом развития доктрины равной защиты, сформулированной в XIV поправке.

\section{Библиография:}

1. Strander v. West Virginia (1880)

2. Plessy v. Ferguson (1896)

3. Burton v. Wilmington Parking Authority (1961)

4. Brawn v. Board of Education (1954)

5. Regents of the University of California v. Bakke (1978)

6. А.А. Мишин, В.А. Власихин. Конституция США: политико-правовой комментарий. М. 1985. С. $296-298$.

7. Stephen A. Siegel. The Origin of the Compelling State Interest Test and Strict Scrutiny. American Journal of Legal History, Vol. 48. №. 4. 2006. P. 393 - 394

\section{References (transliterated):}

1. A.A. Mishin, V.A. Vlasikhin. Konstitutsiya SShA: politiko-pravovoi kommentarii. M. 1985. S. $296-298$.

2. Stephen A. Siegel. The Origin of the Compelling State Interest Test and Strict Scrutiny. American Journal of Legal History, Vol. 48. №. 4. 2006. P. 393 - 394 